\title{
Anaerobic oxidation of fatty acids by Clostridium bryantii sp. nov., a sporeforming, obligately syntrophic bacterium
}

\author{
Marion Stieb and Bernhard Schink \\ Fakultät für Biologie, Universität Konstanz, Postfach 5560, D-7750 Konstanz, Federal Republic of Germany
}

\begin{abstract}
From marine and freshwater mud samples strictly anaerobic, Gram-positive, sporeforming bacteria were isolated which oxidized fatty acids in obligately syntrophic association with $\mathrm{H}_{2}$-utilizing bacteria. Even-numbered fatty acids with up to 10 carbon atoms were degraded to acetate and $\mathrm{H}_{2}$, odd-numbered fatty acids with up to 11 carbon atoms including 2-methylbutyrate were degraded to acetate, propionate and $\mathrm{H}_{2}$. Neither fumarate, sulfate, thiosulfate, sulfur, nor nitrate were reduced. A marine isolate, strain CuCa1, is described as type strain of a new species, Clostridium bryantii sp. nov.
\end{abstract}

Key words: Clostridium bryantii sp. nov. species description - Fatty acid degradation - Anaerobic fermentation Obligate syntrophy - Methanogenesis

Long-chain fatty acids are constituents of fats and lipids whereas short-chain fatty acids are formed as products of anaerobic fermentations (Thauer et al. 1977). In the presence of oxygen, fatty acids are completely degraded by $\beta$-oxidation via acetyl-CoA units. Under anaerobic conditions, fatty acid oxidation probably occurs in a similar manner. The reducing equivalents obtained during $\beta$-oxidation are either used for reduction of inorganic electron acceptors such as sulfate (Pfennig et al. 1981) or have to be released as molecular hydrogen. Since the release of hydrogen in this process is thermodynamically unfavorable, fatty acid-oxidizing acetogenic bacteria can only be cultivated in coculture with hydrogen-utilizing partners which keep the hydrogen partial pressure low (Thauer et al. 1977).

Syntrophic associations of fatty acid-degrading anaerobes have recently been described. Syntrophomonas wolfei is a motile Gram-negative rod which degrades fatty acids with 4 to 8 carbon atoms to acetate, propionate and hydrogen in coculture with hydrogen-scavenging sulfate reducers or methanogens (McInerney et al. 1979). Syntrophobacter wolinii only converts propionate to acetate, hydrogen and carbon dioxide or formate (Boone and Bryant 1980).

We now report on the isolation and properties of an anaerobic sporeforming bacterium degrading fatty acids with 4 to 11 carbon atoms in coculture with hydrogenutilizing anaerobes.

\section{Materials and Methods}

Sources of isolates

The following strains were isolated in coculture with either Methanospirillum hungatei or Desulfovibrio sp. from anaerobic enrichment cultures inoculated with mud samples:

Strain $\mathrm{CuCa} 1$ from marine anoxic mud samples taken near Cuxhaven, FRG, WoCa1 from mud of a creek near Konstanz, strain KoCa2 from anaerobic digestor sludge of the municipal sewage treatment plant, Konstanz, FRG. Desulfovibrio vulgaris strain Marburg was kindly provided by Prof. Dr. R. K. Thauer, Marburg.

Desulfovibrio sp. strain E70 was isolated by Dr. F. Widdel, Konstanz, from anoxic marine sediments with $\mathrm{H}_{2}$ / $\mathrm{CO}_{2}$ and acetate. It utilizes lactate, pyruvate, and formate as substrates for growth.

Methanospirillum hungatei strain $\mathrm{M} 1 \mathrm{~h}$ was isolated from digested sludge of the municipal sewage plant, Göttingen. It utilizes $\mathrm{H}_{2} / \mathrm{CO}_{2}$ or formate as growth substrates.

All procedures for cultivation as well as for analysis of metabolic products were carried out as previously described (Widdel and Pfennig 1981; Schink and Pfennig 1982; Stieb and Schink 1984). The mineral medium for enrichments and further cultivation was carbonate-buffered and sulfidereduced and contained the trace element solution SL 9 (Tschech and Pfennig 1984). The $\mathrm{pH}$ was adjusted to 7.27.4. Freshwater medium contained $0.1 \% \mathrm{NaCl}$ and $0.04 \%$ $\mathrm{MgCl}_{2} \cdot 6 \mathrm{H}_{2} \mathrm{O}$ whereas salt water medium contained $2 \%$ $\mathrm{NaCl}$ and $0.3 \% \mathrm{MgCl}_{2} \cdot 6 \mathrm{H}_{2} \mathrm{O}$.

\section{Isolation and characterization}

Defined mixed cultures were obtained by repeated application of the agar shake culture method described by Pfennig (1978). $0.5 \mathrm{ml}$ of a grown Desulfovibrio sp. culture was added to each tube before gassing with $\mathrm{N}_{2} / \mathrm{CO}_{2}(80 \% / 20 \%)$ mixture. Purity was checked microscopically after growth in mineral medium with $10 \mathrm{mM}$ caproate and $20 \mathrm{mM}$ sulfate or in complex medium (AC-Medium, Difco Laboratories, Detroit, MI, USA) with or without $10 \mathrm{mM}$ caproate and $20 \mathrm{mM}$ sulfate. Growth experiments were carried out at $28^{\circ} \mathrm{C}$. Because cells preferentially grew in flocs, growth could not be followed by optical density measurements. Therefore, metabolic activity was followed by gas chromatographic analysis of substrate degradation and product formation.

All chemicals were of reagent grade and were obtained from E. Merck AG, Darmstadt, FRG; Serva, Heidelberg, FRG; Fluka AG, Neu-Ulm, FRG. 

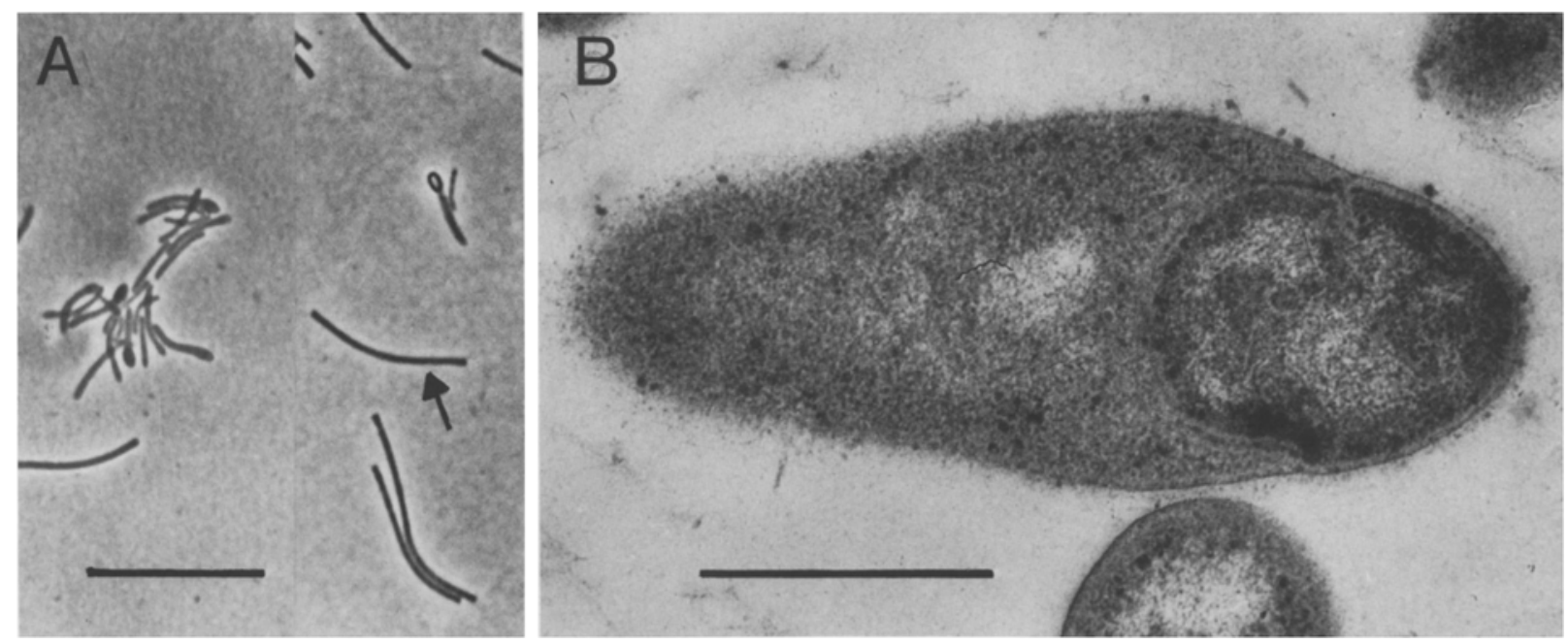

Fig. 1. A Phase contrast micrograph of sporulated cells of Clostridium bryantii strain CuCa1 cocultured with Methanospirillum hungatei. Arrow points at $M$. hungatei cell. Bar represents $10 \mu \mathrm{m}$. B Ultrathin section of a sporulating cell of Clostridium bryantii strain CuCa1. Bar represents $0.5 \mu \mathrm{m}$

\section{Results}

\section{Enrichment, isolation and enumeration}

Enrichment cultures with $10 \mathrm{mM}$ caproate in either freshwater or salt water medium were inoculated with $5 \mathrm{ml}$ of anoxic mud from various habitats. Gas production started after 2-3 weeks indicating substrate degradation. After several transfers, the subcultures contained mainly nonmotile sporeforming rods and rod-shaped fluorescent methanogens. Enrichment cultures with caproate as sole substrate formed acetate and methane as fermentation products.

Isolation was tried in agar shake cultures in mineral medium containing $10 \mathrm{mM}$ caproate, $20 \mathrm{mM}$ sulfate, $5 \mathrm{mM}$ acetate and Desulfovibrio sp. Yellow, disk-shaped colonies appeared after 3 weeks of incubation. After two subsequent dilution series in agar shake cultures, defined mixed cultures could be isolated (strains CuCa1, WoCa1 and $\mathrm{KoCa} 2$ ).

Enumeration of caproate-oxidizing bacteria was carried out by the three-tube most probable number technique (American Public Health Association 1969) in 2 muds of different origin. The medium contained Methanospirillum hungatei as hydrogen scavenger. Tubes were checked for growth by assessment of turbidity and methane formation. 100,000 cells per $\mathrm{ml}$ were found in the mud sample of the creek near Konstanz, and 460 cells per $\mathrm{ml}$ in the Cuxhaven sediment sample. This is in accordance with the assumption that in a marine sediment sulfate-reducing bacteria are the primary fatty acid oxidizers. The prevalent caproate-oxidizing anaerobes found in the highest positive dilution tubes were morphologically similar to strains WoCa1 and CuCa1.

All strains were rod-shaped, sporeforming and nonmotile. Substrate utilization was tested with strains CuCa1 and WoCa1. Both strains degraded the same substrates. Because strains WoCa1 and KoCa1 did not grow well on mineral medium, strain $\mathrm{CuCa} 1$ was chosen for further characterization.

\section{Characterization of strain $\mathrm{CuCaI}$}

Morphology and cytological properties. Cells of strain $\mathrm{CuCa} 1$ were slender, slightly curved, non-motile rods with rounded ends, $0.4 \times 3-6 \mu \mathrm{m}$ in size, occurring singly or in clumps (Fig. 1 A). The Gram reaction was negative to weakly positive. No indication of an outer cell membrane as typical of Gram-negative bacteria could be found in ultrathin sections of sporulating cells (Fig. $1 \mathrm{~B}$ ).

Oval spores, $0.75 \times 1.5 \mu \mathrm{m}$ in size, were formed at the cell ends after at least 4 weeks of incubation. After longer incubation periods spores could also be detected free in the medium. Spores were heat-resistant and survived pasteurization $\left(15 \mathrm{~min}\right.$ at $\left.80^{\circ} \mathrm{C}\right)$.

Nutritional properties and growth characteristics of strain $\mathrm{CuCal}$. Strain CuCa1 grew well in coculture with either Methanospirillum hungatei or Desulfovibrio sp. in mineral medium with $10 \mathrm{mM}$ caproate and at least $1 \% \mathrm{NaCl}$ and $0.15 \% \mathrm{MgCl}_{2} \cdot 6 \mathrm{H}_{2} \mathrm{O}$. Vitamins were present in the medium, however, were not necessary for growth in salt water medium for at least 5 subsequent transfers. No growth was found under aerobic conditions. Phosphate completely inhibited growth at concentrations higher than $10 \mathrm{mM}$.

The only substrates utilized were fatty acids with $4-11$ carbon atoms including 2-methylbutyrate. Other substrates such as propionate, fatty acids with $12-18$ carbon atoms, isobutyrate, 3-methylbutyrate, 3-hydroxybutyrate, crotonate, acetoacetate ethyl ester, pyruvate, lactate, succinate, fumarate, glycerol, glucose, fructose, ribose or yeast extract were not metabolized. Utilization of electron acceptors was tested with cultures inoculated with pasteurized sporulated cells. Neither fumarate nor sulfate, thiosulfate, sulfur or nitrate was reduced. Growth was observed at $28^{\circ} \mathrm{C}$ and $34^{\circ} \mathrm{C}$, but not at $20^{\circ} \mathrm{C}$ and $40^{\circ} \mathrm{C}$. The $\mathrm{pH}$ limits were $\mathrm{pH}$ 6.5 and 7.5. Substrate degradation and product formation during growth on caproate under optimal conditions is presented in Fig. 2. Independently of the hydrogen-utilizing partner, butyrate was excreted during caproate degradation, and was utilized later on. The doubling time as estimated from acetate formation rates was about $72-96 \mathrm{~h}$ in both cases, however, cocultures with Desulfovibrio sp. had shorter lag periods after transfer than those with $M$. hungatei.

The relationship between substrate utilization and product formation is given in Table 1. Even-numbered fatty acids were degraded to acetate and sulfide or methane, whereas 

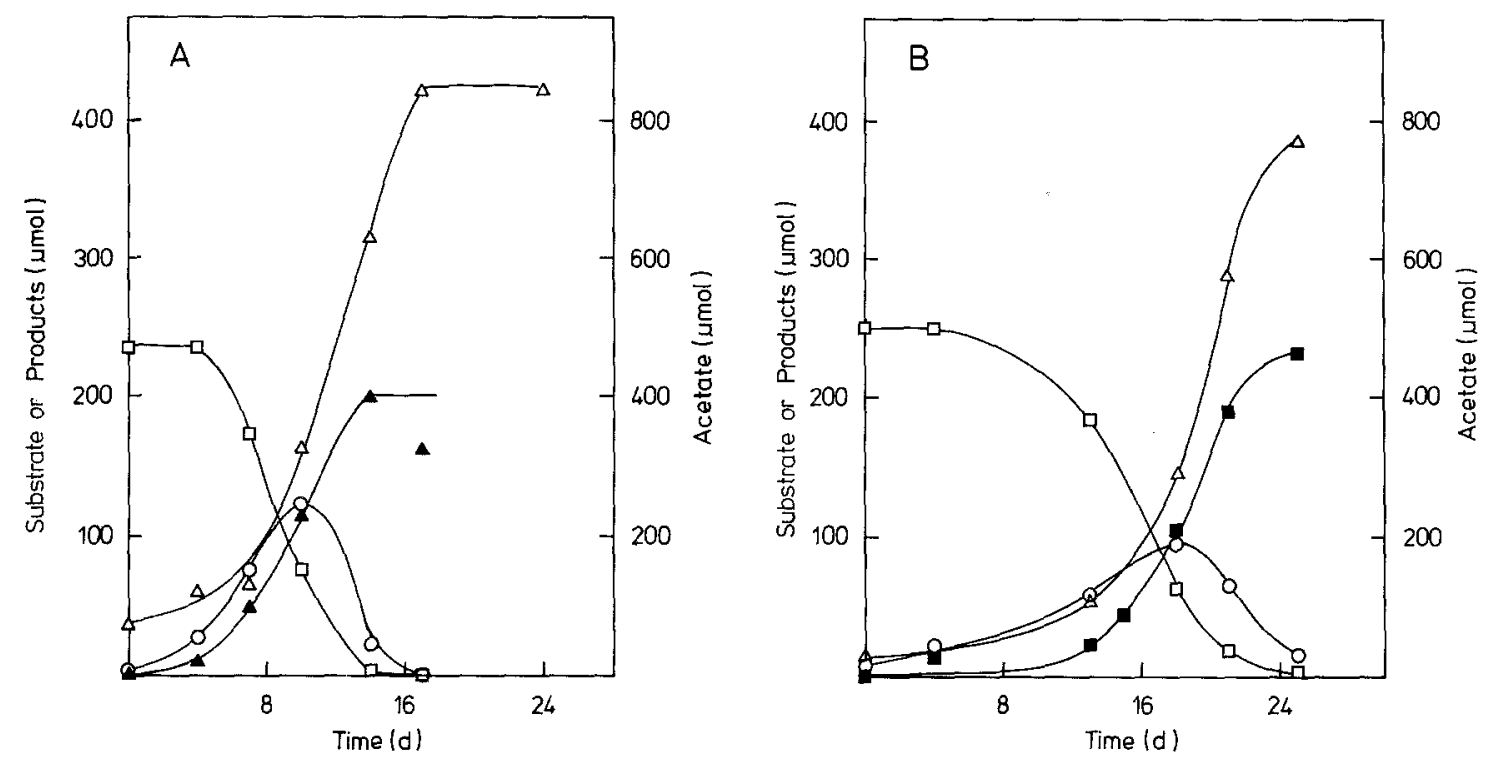

Fig. 2. Time course of caproate degradation and product formation by Clostridium bryantii strain CuCa1, $\mathbf{A}$ in coculture with Desulfovibrio sp., B in coculture with Methanospirillum hungate $i$. $\square$, caproate; $\triangle$, acetate; $O$, butyrate; $\boldsymbol{\Lambda}$, sulfide; $\mathbf{\square}$, methane

Table 1. Stoichiometry of fermentation by strain $\mathrm{CuCa} 1$ in coculture with either Desulfovibrio sp. strain E70 or Methanospirillum hungatei. Experiments were carried out in screw cap tubes with butyl rubber septa

\begin{tabular}{|c|c|c|c|c|c|c|}
\hline \multirow[t]{2}{*}{ Substrate } & \multirow[t]{2}{*}{ No. of C-atoms } & \multirow{2}{*}{$\begin{array}{l}\text { Amount of substrate } \\
\text { degraded } \\
\text { [ } \mu \text { mol] }\end{array}$} & \multicolumn{4}{|c|}{ Products $[\mu \mathrm{mol}]$} \\
\hline & & & Acetate & Proprionate & $\mathrm{HS}^{-\mathrm{a}}$ & $\mathrm{CH}_{4}{ }^{\mathrm{b}}$ \\
\hline Butyrate & 4 & 200 & 398 & & 75 & \\
\hline Butyrate & 4 & 100 & 184 & & & 53 \\
\hline Valerate & 5 & 200 & 216 & 183 & 76 & \\
\hline Valerate & 5 & 100 & 104 & 104 & & 56 \\
\hline 2-Methylbutyrate & 5 & 200 & 204 & 194 & 131 & \\
\hline Caproate & 6 & 200 & 613 & & 163 & \\
\hline Caproate & 6 & 200 & 590 & & & 182 \\
\hline Heptanoate & 7 & 100 & 200 & 77 & 73 & \\
\hline Caprylate & 8 & 20 & 78 & & 34 & \\
\hline Caprylate & 8 & 10 & 36 & & & 14 \\
\hline Pelargoate & 9 & 20 & 68 & 19 & 30 & \\
\hline Caprinate & 10 & 20 & 126 & & & \\
\hline Undecanoate & 11 & 20 & 95 & 19 & 38 & \\
\hline
\end{tabular}

a In coculture with Desulfivibrio sp.

b In coculture with Methanospirillum hungatei

odd-numbered fatty acids including 2-methylbutyrate were degraded to acetate, propionate and sulfide or methane. The stoichiometry of product formation is in accordance with the following fermentation equations for degradation of caproate in coculture with either Desulfovibrio sp. or Methanospirillum hungatei:

$$
\begin{gathered}
\mathrm{C}_{6} \mathrm{H}_{11} \mathrm{O}_{2}^{-}+\mathrm{SO}_{4}^{2-} \rightarrow 3 \mathrm{C}_{2} \mathrm{H}_{3} \mathrm{O}_{2}^{-}+\mathrm{HS}^{-}+\mathrm{H}^{+} \\
\Delta \mathrm{G}_{0}^{\prime}=-58.3 \mathrm{~kJ} / \mathrm{mol} \\
\mathrm{C}_{6} \mathrm{H}_{11} \mathrm{O}_{2}^{-}+\mathrm{H}_{2} \mathrm{O}+\mathrm{HCO}_{3}^{-} \rightarrow 3 \mathrm{C}_{2} \mathrm{H}_{3} \mathrm{O}_{2}^{-}+\mathrm{CH}_{4}+\mathrm{H}^{+} \\
\Delta \mathrm{G}_{0}^{\prime}=-40.83 \mathrm{~kJ} / \mathrm{mol}
\end{gathered}
$$

Gibbs free energies were calculated after published tables (Thauer et al. 1977).

\section{Discussion}

The bacteria described in the present study represent another species of obligately syntrophic fatty acid-oxidizing anaerobes similar to Syntrophomonas wolfei (McInerney et al. $1979,1981)$. Similar to this species, our isolates are specialized for syntrophic oxidation of fatty acids and do not use any other kind of substrates. However, the range of substrates used by our isolates is broader than that reported for $S$. wolfei which only uses fatty acids up to 8 carbon atoms. Moreover, our isolates are able to degrade also 2-methylbutyrate, a product of anaerobic degradation of leucine (Barker 1981). The new strains appear to be better adapted to long-chain fatty acids than $S$. wolfei: Enrich- 
ments and enumerations with caproate as substrate always yielded bacteria similar to those described in this paper whereas enrichments with butyrate as substrate always led to bacteria similar to $S$. wolfei. However, the range of utilizable fatty acids is limited also for our strains, and in spite of numerous efforts we so far did not succeed in isolation of syntrophic bacteria able to degrade long-chain fatty acids like palmitate or stearate. It appears that anaerobic degradation of fatty acids is subdivided into two different ranges, the short-chain and the long-chain range, and different types of bacteria are specialized for either one.

During degradation of caproate, our isolates excreted butyrate as an intermediate product which later on was oxidized to acetate. If medium-chain fatty acids are excreted during long-chain fatty acid degradation in a similar manner, they could well serve as substrates for our isolates.

Our isolates are the first obligately syntrophic anaerobes which are Gram-positive. Lack of an outer cell membrane poses the question on the localization of hydrogenases in these bacteria. So far, periplasmic hydrogenases were supposed to be useful, if not necessary for an efficient interspecies hydrogen transfer (Bell et al. 1974), and may even be one of the reasons why sulfate reducers can outcompete methanogens for hydrogen (Kristjansson et al. 1982). Our isolates provide evidence that also a different hydrogenase localization can be sufficiently competitive.

Unfortunately, our isolates were not able to grow on partly unsaturated fatty acids. Disproportionation of e.g. crotonate to acetate and butyrate would allow growth of these bacteria in pure culture independent of syntrophic partners. Enrichments with crotonate and 3-hydroxybutyrate recently led to the isolation of a new metabolically very versatile anaerobe which, however, did not participate in interspecies hydrogen transfer (Stieb and Schink 1984).

The ability of our isolates to form spores make these organisms very handy for transfer between different hydrogen-scavenging partners. Moreover, this may allow to cultivate this organism free of contaminating partners in membrane-separated mixed culture systems. Experiments in this field are in progress, however, were not successful so far.

\section{Taxonomy}

As obligately anaerobic, sporeforming, non-sulfate-reducing bacterium, our isolate has to be classified with the genus Clostridium sp. (Buchanan and Gibbons 1974). The range of substrates utilized and its obligately syntrophic dependence on $\mathrm{H}_{2}$-scavenging partners distinguishes strain $\mathrm{CuCa} 1$ from all other Clostridium $\mathrm{sp}$. Therefore, a new species, Clostridium bryantii is proposed.

C. bryantii sp. nov. bry. an' ti. i. M. L. gen. n. named for Marvin P. Bryant, who pioneered studies on syntrophic methanogenic associations.

Rod-shaped cells, $0.4 \times 4.5-6 \mu \mathrm{m}$ in size with rounded ends. Non-motile, slightly curved. Gram reaction negative to weakly positive; no outer cell membrane. Spores terminal, oval, $0.75 \times 1.5 \mu \mathrm{m}$ in size.

Strictly anaerobic chemoorganotroph. Fatty acids with 4-11 carbon atoms and 2-methylbutyrate utilized for growth and fermented to acetate and $\mathrm{H}_{2}$ or to acetate, propionate and $\mathrm{H}_{2}$ in syntrophic association with hydrogenscavenging anaerobes. No other organic acids, no sugars or alcohols metabolized. Sulfate, sulfur, thiosulfate, nitrate, or fumarate not reduced.

Selective enrichment in mineral medium with caproate as substrate. $\mathrm{pH}$ range: $6.5-7.5$. Growth at $28^{\circ} \mathrm{C}$ and $34^{\circ} \mathrm{C}$, not at $20^{\circ} \mathrm{C}$ and $40^{\circ} \mathrm{C}$. Type strain: CuCa1, DSM 3014A, B (A: coculture with Desulfovibrio sp., B: coculture with Methanospirillum hungatei), deposited in Deutsche Sammlung von Mikroorganismen, Göttingen, FRG.

Acknowledgements. The authors are indebted to Prof. Dr. Norbert Pfennig for support and valuable criticism as well as to Dr. Walther Johannssen for preparing the ultrathin sections. This work was supported by the Deutsche Forschungsgemeinschaft.

\section{References}

American Public Health Association Inc (ed) (1969) Standard methods for the examination of water and wastewater including bottom sediments and sludge. New York, pp 604-609

Barker HA (1981) Amino acid degradation by anaerobic bacteria. Ann Rev Biochem 50:23-40

Bell GR, LeGall J, Peck Jr HD (1974) Evidence for the periplasmic location of hydrogenase in Desulfovibrio gigas. J Bacteriol 120:994-997

Boone D, Bryant M (1980) Propionate-degrading bacterium, Syntrophobacter wolinii sp. nov. gen. nov., from methanogenic ecosystems. Appl Environ Microbiol 40:626-632

Buchanan RE, Gibbons NE (eds) (1974) Bergey's manual of determinative bacteriology, 8th ed. Williams and Wilkins, Co., Baltimore

Kristjansson JK, Schönheit P, Thauer RK (1982) Different $K_{\mathrm{s}}$ values for hydrogen of methanogenic bacteria and sulfate reducing bacteria: an explanation for the apparent inhibition of methanogenesis by sulfate. Arch Microbiol 131:278-282

McInerney MJ, Bryant M, Pfennig N (1979) Anaerobic bacterium that degrades fatty acids in syntrophic association with methanogens. Arch Microbiol 122:129-135

McInerney MJ, Bryant M, Hespell RB, Costerton JW (1981) Syntrophomonas wolfei gen. nov. sp. nov., an anaerobic, syntrophic, fatty acid oxidizing bacterium. Appl Environ Microbiol 41:1029-1039

Pfennig N (1978) Rhodocyclus purpureus gen. nov. and sp. nov., a ring-shaped, vitamin $B_{12}$-requiring member of the family Rhodospirillaceae. Int J Syst Bacteriol 28:283-288

Pfennig N, Widdel F, Trüper HG (1981) The dissimilatory sulfatereducing bacteria. In: Starr MP, Stolp H, Trüper HG, Balows A, Schlegel HG (eds) The prokaryotes, Vol I. Springer, Berlin Heidelberg New York, pp 926-940

Schink B, Pfennig N (1982) Fermentation of trihydroxybenzenes by Pelobacter acidigallici gen. nov. sp. nov., a new strictly anaerobic, non-sporeforming bacterium. Arch Microbiol 133:195201

Stieb M, Schink B (1984) A new 3-hydroxybutyrate fermenting anaerobe, Ilyobacter polytropus gen. nov. sp. nov., possessing various fermentation pathways. Arch Microbiol (in press)

Thauer RK, Jungermann K, Decker K (1977) Energy conservation in chemotrophic anaerobic bacteria. Bacteriol Rev 41:100180

Tschech A, Pfennig N (1984) Growth yield increase linked to caffeate reduction in Acetobacterium woodii. Arch Microbiol 137:163-167

Widdel F, Pfennig N (1981) Studies on dissimilatory sulfate-reducing bacteria that decompose fatty acids. I. Isolation of new sulfate-reducing bacteria enriched with acetate from saline environments. Arch Microbiol 129:395-400

Received August 8, 1984/Accepted August 19, 1984 